\title{
Understanding the healthcare needs of Sudanese refugee women settling in Australia
}

\author{
Lisa Peters, Sharon L. Bourke, Janet A. Green, Elianna Johnson, Ligi Anish, Linda K. Jones \\ Federation University, Australia
}

Received: May 1, 2020

Accepted: June 9, 2020

Online Published: June 16, 2020

DOI: $10.5430 / \mathrm{cns} . v 8 \mathrm{n} 2 \mathrm{p} 40$

URL: https://doi.org/10.5430/cns.v8n2p40

\begin{abstract}
Objective: Explore the healthcare needs of Sudanese refugee women settling in Australia.

Background: Refugees from Sudan are the fastest growing community in Australia. Nurses who care for people from the Sudan will be required to be familiar with the needs of this emerging community and offer culturally competent and safe care.

Methods: Integrative review of the literature.

Results: Sudan is one of the countries in Africa where the practice of female genital mutilation (FGM), cutting or circumcision is considered a social norm. This is a deeply rooted traditional cultural practice that is still prevalent in many developing countries. Healthcare professionals in Australia are ill equipped to care for women and children who have undergone this procedure. This paper explores the Sudanese refugee community in Shepparton, Victoria to explore the nursing considerations caring for women affected by FGM within the Australian health care context.

Conclusions: There is a need for more education in undergraduate, postgraduate and continuing professional education on the healthcare needs of women who have undergone female genital mutilation in order to provide appropriate care and support for these women.
\end{abstract}

Key Words: Female genital mutilation, Cultural safety, Sudan refugees, Nurse and midwife

\section{INTRODUCTION}

The Republic of the Sudan is in North-Eastern Africa. It is a land locked country bordered by Egypt (south), Libya (northeast), Chad (West), Central African Republic (south-west), South Sudan (south), Ethiopia (south-east), Eritrea (east) and the Red Sea (north-east). The World Health Organisation's ${ }^{[1]}$ data show Sudan to be poor country with a population of $39,579,000$, a gross national product (GNP) per capita US $\$ 2,370$, a life expectancy of 63 for men and 67 for women. ${ }^{[1]}$

Sudan has a very long history of numerous changes in dynasty dictating extensive religious laws. There has been severe and constant unrest in Sudan since the outbreak of a deadly civil war in 1983. The political turmoil continued when the newly elected country was formed in 2011 and has severely affected the people and stirred several further armed conflicts within the country. ${ }^{[2]}$ The conflicts in these regions are compounded by forceful imposition of Shari ah law on non-Muslims and other minorities. The people in South Sudan have been extremely tormented by dangerous and difficult situation arising from armed conflicts which have led to a significant economic decline in the country. As a result, the population in South Sudan is experiencing severe starvation and significant health problems. The aggravating economic condition and conflicts has forced millions of Sudanese to flee and take shelter in different countries

*Correspondence: Sharon L. Bourke; Email: s.bourke@ federation.edu.au; Address: Federation University, Australia. 
as refugees. Women and children are the most affected due to discrimination, sexual violence and a deep seated culture of denial around rape. ${ }^{[2]}$ Consequently, more than 80 percent of people fleeing South Sudan are women and children, with children accounting to 63 percent of the refugee population. ${ }^{[3]}$ Sudan, particularly South Sudan faces the largest refugee crises in Africa and known to be the third largest refugee crises in the world. ${ }^{[3]}$

The term 'refugee' is defined as an individual who crosses international borders to escape war, violence, conflict or persecution for reasons of race, religion, nationality, or political opinion. ${ }^{[3]}$ The World Health Organisation ${ }^{[2]}$ identifies that 68.5 million individuals have been displaced globally with 25.4 million seeking refuge internationally. Displacement increases the vulnerability of refugees due to increased risk of diseases from poor living conditions and sanitation. ${ }^{[2]}$ Many of these refugees come to Australia. ${ }^{[2,3]}$

Sudan is one of the countries in Africa where the practice of female genital mutilation (FGM), cutting or circumcision is considered a social norm. ${ }^{[4]} \mathrm{WHO}^{[2]}$ defines FGM as the removal of external genitalia (partial or total removal) or other injuries to the female genital organs for non-medical reasons. This is a deeply rooted traditional cultural practice that is still prevalent in many developing countries. ${ }^{[5]}$ Healthcare professionals in Australia are ill equipped to care for women and children who have undergone this procedure. This paper explores the Sudanese refugee community in Shepparton, Victoria to explore the nursing considerations caring for women affected by FGM within the Australian health care context.

\section{SEARCH STRATEgY/METHODOLOGY}

To facilitate an integrative review of the literature, a search of the literature was performed from multiple health-care related databases: including CINAHL, Google Scholar and MEDLINE and grey literature. No results were found using the search terms FGM, Sudanese refugees in Australia, nursing and health care. Once broadened the search resulted in 279 results with some crossover between databases. The search was limited to research in English and articles published since 2010. The search was not limited by rigorous study design. Each study was screened through the abstract and title for relevance to an Australian nursing perspective.

\section{HEALTH INEQUALITIES AND INEQUITIES ON ARRIVAl in Victoria, Australia}

Shepparton is a regional town in the north-east of Victoria, Australia. It is a service town of approximately 29,500 people supported by irrigation-based fruit growing, dairy and other agricultural industries. ${ }^{[6]}$ Often referred to as the "food bowl" of Australia, the region supports industries that are some of the largest food-based manufacturing industries in the country. ${ }^{[6]}$ Historically migrants who sometimes lacked recognisable skills and with limited English were encouraged to settle in this regional area due to good work opportunities and this is still true today. ${ }^{[7]}$ In fact, Shepparton and surrounds is fast becoming internationally renowned not just for its agricultural offerings but for being a centre that is accepting of many people from diverse backgrounds as either migrants or asylum seekers. ${ }^{[8]}$ Sudanese settling here started from about 2006 with approximately 80 people increasing to 1,000 people in $2015 .{ }^{[6]}$

The number of refugees Australia accepted and resettled during 2018 was $12,706,{ }^{[6,9]}$ yet there is limited availability of community health care services that are focused on refugees and their health requirements in comparison to local Australian-born people. ${ }^{[10]}$ In addition, there is just one public hospital in Shepparton that caters for the health care of 107,000 people in the district, with $11 \%$ of these born in non-English speaking countries. ${ }^{[11]}$

Shepparton, however, is a disadvantaged location with low socioeconomic status (SES) rated as one of the top $20 \%$ disadvantaged areas nationwide. ${ }^{[6]}$ SES includes income, education levels, financial security, quality of life and insights to social status. ${ }^{[12]}$ Due to the disadvantaged location and low SES, life can be challenging for Australian-born residents and even more so for Sudanese refugees to live in Shepparton. For example, the median weekly income for Australian-born residents in Shepparton is \$565 compared to the average of $\$ 673$ across Australia. ${ }^{[9]}$ With many Sudanese uneducated in their own language, illiterate in English, and unskilled, it is difficult for them to find employment with a decent income. ${ }^{[10]}$ Language barriers, lack of networks, poor literacy skills and ineffective communication may result in Sudanese refugees being unable to learn Australian cultural rules, standards and expectations. This in turn affects their employability and acceptance into the community, often resulting in them feeling confused and overwhelmed. ${ }^{[6]} \mathrm{Em}$ ployment undertaken by Sudanese women include seasonal work, farming, laundry, teaching and community work. ${ }^{[6]}$

Upon resettling to Shepparton, there are complex health care needs and wellbeing concerns that Sudanese women in particular face when integrating into the community. ${ }^{[10]}$ These complex needs include: culture shock, breakdown of their culture and values, racism, discrimination, social isolation, dietary changes, nutrition-related ailments, unemployment, and lack of medical care. ${ }^{[13]}$ Health care availability is compromised for refugees because of an unfamiliar health care system, unaffordability of health care services and ineffective 
communication between refugees and health professionals resulting in refugees falling through the gaps of services. ${ }^{[10]}$ Depending on the visa class or refugee status, health care may be partially or fully covered by Medicare. As a result, Sudanese females may not have access to general practitioners (GP) and health care workers in Shepparton, hence, are less likely to seek medical treatment. Additionally, Sudanese women may not be able to afford a car, hence rely on the public bus transport to attend health care consultations.

Sudanese women have language barriers due to limited or no English skills ${ }^{[6]}$ Community members have reported a substantial lack of interpreters available to translate in the local area, therefore, unable to meet the demands for services. ${ }^{[6]}$ In addition, health practitioners often did not utilise this service due to time constraints because of the additional time spent waiting to access a translator. ${ }^{[6]}$ Sudanese women, who rely on friends or family to translate, may result in inaccurate or censored communication resulting in poor assessment data and potentially poorer health outcomes. Building trust in an interpreter service as a means of improving cultural safety is essential for this minority group of women. ${ }^{[14]}$

Women with poor English language skills tend to have lower health screening rates resulting in a poor health outcome compared to those born in Australia. ${ }^{[14]}$ This is likely due to limited or lack of preventative health care in Sudan and unfamiliarity in the need for health care. ${ }^{[14]}$ Age and gender roles in Sudanese cultures are significantly different to those in Australia, and consultations with doctors of the opposite sex may be confronting, confusing and overwhelming to these women. ${ }^{[6]}$

\section{Female Genital mUtilation (FGM)}

Globally it is estimated that approximately 200 million women have undergone FGM, with more than $70 \%$ of these women originating from African countries such as Sudan. ${ }^{[15]}$ Annually, approximately 3 million females will undergo FGM procedures globally. ${ }^{[15,16]}$ Prior to leaving their country, many Sudanese women have had FGM undertaken. ${ }^{[17]}$ FGM refers to the intentional procedures to partially or entirely remove female external genital tissue, or non-medical injury to the genitalia. ${ }^{[3]}$ There are no medical or health reasons for FGM. ${ }^{[16]}$

FGM procedure is primarily performed in females ranging from infancy to 15 years. ${ }^{[15]}$ There are four distinct types of FGM practice: Type I is the partial or complete removal of clitoris and surrounding structures. Type II involves excision of the clitoris with partial or total excision of the labia minora. The labia majora remains intact. Type III or infibulation is the most extreme category and involves the removal of all or part of the external genitalia and stitching the two cut ends together leaving a small opening to allow urine and menstrual flow to pass. The last Type IV involves all other harmful genital procedures such as piecing, pricking and stretching of the labia. ${ }^{[4,15,16]}$ The most severe form, type III, is practiced among Sudanese populations. ${ }^{[18]}$

The tradition of FGM is thought to have originated in Egypt some 4,000 years ago, outdating both Biblical and Koran teachings. ${ }^{[15,16,19]}$ Traditional cultural beliefs are that the clitoris is offensive and a smooth vulva is aesthetically pleasing. FGM is a cultural ritual that has a high social value entrenched in custom and tradition and considered as normal. ${ }^{[18,19]}$ The reasons for the procedure relate to culture and include cleanliness and hygiene, preservation of virginity, preventing promiscuity through the pain of opening a vaginal seal, increases fertility, and decreases sexual pleasure for the female but increases it for the male. ${ }^{[19,20]}$ FGM is considered the natural progression of female development and aids in the preparedness of adulthood and marriage. ${ }^{[16]}$ Generally, it is women that support, defend and command this ancient and culturally based procedure, due to their belief that an uncircumcised female is unable to marry or be accepted into society. ${ }^{[20,21]}$ Refusal may result in the community ostracising the female.

FGM is a secretive practice and considered as normal in the countries that practice this custom. Females with genital mutilation may not identify as impacted by this procedure due to social stigmatization, especially if they have been displaced. ${ }^{[15]}$ Furthermore, some practices require the swearing of secrecy oaths as part of the ritual of FGM. ${ }^{[22]}$ FGM is a direct violation of universal human rights. ${ }^{[15]}$ From an Australian perspective, FGM is illegal with laws prohibiting people performing or assisting to perform the procedure. ${ }^{[6,15]}$ Under current Australian law it is also illegal to removal a child to have the procedure completed internationally.

\section{THE IMPACT ON HEALTH FOLLOWING FGM}

There are many short and long-term complications caused by FGM, depending on the severity of the procedure. Initial complications occur because FGM is performed by nonmedical practitioners with crude, unsharpened, non-sterilised instruments, without anaesthesia or follow-up care ${ }^{[23]}$ and include bleeding, shock, sepsis and death. Long term complications include chronic genital pain, bleeding, urinary tract infections, bacterial vaginosis, menstrual abnormalities, sexual discomfort, STI, Hepatitis B, Hepatitis C, HIV, cysts, ulceration, pelvic inflammatory disease, infertility, ectopic pregnancy, and scar tissue formation. ${ }^{[16]}$ Furthermore, FGM 
may have severe psychological impacts on the individual leading to severe anxiety, depression, tokophobia (fear of pregnancy and childbirth), and post-traumatic stress disorder (PTSD) from the physical and psychological trauma. ${ }^{[2]}$

If the woman manages to get pregnant, she may experience complications during pregnancy, such as urinary tract infections. Depending on the type of circumcision the biggest issues can occur during the labour and birth, with dystocia (difficult labour and birth) being common and increased risk of bleeding and need for assisted birth, especially caesarean. ${ }^{[5,6,24]}$

Pregnant women with type III FGM will need to undergo deinfibulation prior to birth. ${ }^{[18]}$ Deinfibulation is considered a minor procedure involving a vertical incision to the scar to expose the urethra and vagina. This procedure is either undertaken during pregnancy or prior to birth. ${ }^{[18]}$ If the practice is to perform deinfibulation during pregnancy, women are more likely to present when they are in labour and thereby delay this procedure. ${ }^{[25]}$ Postnatally women are at increased risk of bleeding due to the deinfibulation as well as possible damage to genital structures. If the wound is not repaired after birth, the edges will seal and heal to form a pseudo-infibulation. The edges of the wound need to be sutured and women and partners adequately educated and counselled about the health implications. Women and partners may request re infibulation for many reasons, one being the fear of rejection by partners if not done. Women may avoid hospital for birth where there are strong rules against re infibulation. ${ }^{[5]}$

Neonates born to mothers who have undergone FGM may have poor outcomes that are directly attributable to FGM in the mother. ${ }^{[1]}$ The risk of infant perinatal death was significantly greater for infants born to mothers with FGM types II and III when compared with infants born to mothers without FGM. Babies born to mothers with Type II or III FGM were more likely to have experienced fetal distress or needed resuscitation. This meant that the baby was more likely to die during or immediately after birth. ${ }^{[1]}$ The risk of stillbirth is increased with FGM types I and II as a result of prolonged second stage of labour is thought to be a result of decreased elasticity of perineal tissue and actual obstruction owing to infibulation. ${ }^{[26,27]}$ Deinfibulation may also be performed on women to alleviate or resolve the complications associated with type III FGM. ${ }^{[15,16,22]}$ Due to the different categories of FGM, it may be impossible to restore normal anatomy. Deinfibulation is predominately completed prior to gynaecological procedures such as treatment for miscarriage and treatment for recurrent urinary tract infections. ${ }^{[15,16,22]}$

It would be convenient for Australian health professionals to believe they will only see women who have been victims of FGM. There are, however, babies and children who have undergone FGM that will be identified. FGM is seen in paediatric clinical practice within Australia. ${ }^{[15]}$ An Australian study found that paediatricians identified female children who had been "cut" aged between 4.8 months and 17.6 years (median 10.7 years). ${ }^{[28]}$ The majority $(89.7 \%)$ of the children were identified through refugee screening by the paediatricians and were born in Africa, but three were born in Australia. All parents were born overseas. ${ }^{[28]}$ It is concerning that two of the girls born in Australia to overseas born parents, had FGM performed in Australia. ${ }^{[28]}$ It is also not uncommon for women to send their female children back to the motherland to have the FGM procedure performed. ${ }^{[4,19]}$ If a health professional is asked to see a baby/child immediately after the FGM they would need to assess for signs of acute blood loss, sepsis and urinary retention. Treatment will include antibiotics, analgesia, tetanus toxoid and possible urinary catheterisation. ${ }^{[28]}$

\section{THE ROLE OF NURSES AND MIDWIVES}

A key consideration here is that women from Sudan had the FGM procedure undertaken when they were a child and for them it is considered to be a normal process in the transition to being a woman. ${ }^{[25,29]}$ This means that such women are not necessarily aware that they are different to women who have not had FGM performed. In most countries where FGM is practised it is a cultural norm or tradition, and many of the women will use this argument for its continuation. ${ }^{[30,31]}$ In fact, the cultural norm of the ideals of femininity, modesty, marriageability and fear of rejection by their community, will see many of these women willing to continue this practice for their own daughters in preparation for adulthood and marriage. The belief that women are clean and beautiful after the removal of body parts considered unclean or unfeminine, and ensuring premarital virginity, are powerful motivators to perpetuate the practice of FGM. ${ }^{[30,31]}$

Women are, therefore, not necessarily aware that they need to reveal to health professionals that they have been "cut". 25,29$]$ The women may also feel uncomfortable revealing that she has been "cut" or seeking help for any problems she is experiencing due to lack of translators, female practitioners, disclosure to peers to translate, or fear of discrimination by health care workers. ${ }^{[25,29]}$ This may also be due to the fact that FGM women may believe that any problems they are having are normal because FGM is normal to them and not be aware that some problems can be easily addressed. If Sudanese women are hesitant to seek health care due to the morbidities of FGM, they may be isolated from other treatments such as cervical screening, increasing their risk for cervical cancers. ${ }^{[14]}$ As a consequence, health professionals 
may not realise that women have had FGM performed, until a women presents during pregnancy and/or childbirth, when the effects become problematic. ${ }^{[21]}$ Nurses and midwives need to be more aware that women from certain cultural backgrounds may have FGM and therefore be prepared to ask the question. ${ }^{[25]}$ Receiving education from women who have experienced FGM would help nurses and midwives gain an authentic understanding of the "lived experience" of these women, which could improve the care they provide.

Although FGM is relevant to all health professionals who provide care to females of any age, most lack knowledge about FGM. ${ }^{[28]}$ For instance, Zurynski et al. ${ }^{[15]}$ reports that only $14.5 \%$ of Australian paediatricians had attended education surrounding FGM with most Australian services lacking in FGM education. Nurses and midwives have also been reported to have a lack of knowledge regarding the care of women with FGM. ${ }^{[4,25]}$ Women have reported that they have been surprised that nurses and midwives were not experienced in managing FGM which undermines women's confidence and increases their hesitancy in accessing services and to even speak about FGM. ${ }^{[25]}$ This has resulted in women feeling anxious and fearful because of the lack of ability of the nurses and midwives that they were trusting to care for them. ${ }^{[29]}$ Importantly, it has been found that nurses and midwives specifically lacked knowledge regarding the cultural aspects important to providing culturally competent care. The result was that nurses and midwives had been reported to not discuss important aspects such as painful urination and sexual intercourse or even pain management issues after the women with FGM had given birth. ${ }^{[19]}$ It is possible that nurses and midwives do have some knowledge but lack the confidence and skills to ask women about FGM due to insufficient understanding of the cultural aspects. ${ }^{[25]}$

Where nurses and midwives have tried to discuss FGM sensitively, it has been reported that women viewed their efforts as intrusive and inappropriate. ${ }^{[4]}$ Women reported cultural insensitivity from health professionals generally. For instance, being more interested in the actual FGM then gaining an understanding and respecting the cultural practice has been reported in the literature. ${ }^{[19]}$ Women have also reported health professionals making hurtful comments and wanting to call in a colleague to view the perineum, ${ }^{[25]}$ as well as making the assumption that women with FGM were sexually flawed or being disgusted by the practice. This lack of understanding extends to women with FGM being roughly touched and not being conscious of the discomfort women would feel as a consequence. ${ }^{[25]}$ Undoubtedly, nurses and midwives may be shocked and dismayed at what they consider to be a barbaric practice. ${ }^{[30,31]}$ With the level of cultural normality viewed by women who have undergone FGM, it will not be helpful for health professionals to openly disparage the practice. Empathy and understanding are required because women with problems from FGM may not seek care from health care professionals due to fears of repercussions, shame, or lack of knowledge. ${ }^{[23]}$

When women have an open relationship with nurses/midwives it is reported that they felt more comfortable discussing FGM. ${ }^{[25]}$ Needless to say, it is also important that the health professional has some knowledge of FGM, and are willing to discuss and support issues around FGM. ${ }^{[25]}$ Otherwise women reported that they felt embarrassed and uncomfortable discussing such issues. It would be hard enough as it is with these women being potentially away from their families and feeling very lonely. ${ }^{[29]}$

It is important to be aware about cultural and religious issues and phrase questions in a culturally sensitive way ${ }^{[25]}$ Nurses and midwives do not necessarily have the education and skills in this area, and more is needed. A non-judgemental approach is the most important attribute of health care professionals caring for any woman who has undergone FGM. Culturally sensitive questions that are non-judgemental and using a female interpreter trained in FGM would be an advantage. ${ }^{[21]}$

An increasing awareness of psychological concerns for women who have had FGM is vital to provide effective care for these women. ${ }^{[21]}$ Moreover, not only does the women with FGM experience physical pain and suffering, but the experience of having FGM may cause psychological trauma. ${ }^{[16]}$ Kahn's ${ }^{[32]}$ findings of female's early recollections of awareness of FGM reveals a rite of passage, powerlessness to resist FGM and knowledge of retribution upon those who refused the procedure. There was fear of the unknown of when FGM was going to occur. Victims knew it would inevitably occur, but were usually not told when, which instilled anticipatory fear. ${ }^{[32]}$ It is this element of fear that was recalled by the Sudanese females interviewed. ${ }^{[32]}$ Routine care such as pap smear tests and medical examinations may trigger flashbacks in response. Bryant et al. ${ }^{[33]}$ emphasised that by addressing psychological requirements of refugees such as PTSD, depression and anxiety, there are substantial mental health benefits not only with the adults, but with their children's emotional health as well. PTSD affects the long-term health of not only the victims, but their parenting skills. ${ }^{[33]} \mathrm{Re}$ ferring them to specialised refugee trauma counselling for treatment of psychological and emotional symptoms is essential. ${ }^{[14]}$ In summary, Von Rege and Campion ${ }^{[22]}$ have outlined good practice in relation to how to care for women 
with FGM, including communication, education counselling and mental health.

Shepparton, Victoria is a multi-ethnic community with females originating from Sudan where the practice of FGM is prevalent. ${ }^{[34]}$ Health care services are faced with a growing population of females with physical and psychological trauma from the practice of FGM. ${ }^{[34]}$ There is a high incidence of mental health disorders in refugee populations compared to those that are not refugees. ${ }^{[33]}$ Some Sudanese believe that mental health issues are related to a curse or witches and therefore hesitant to seek any medical help. ${ }^{[6]}$

Goulburn Valley Health in Australia makes no mention of treatments or specialists in FGM, therefore Sudanese women in Shepparton may have difficulty connecting with health services. ${ }^{[11]}$ The Royal Women's Hospital Melbourne has a deinfibulation clinic that provides operations to young females with FGM, yet there is no evidence of this service being provided in Shepparton's public hospital. With limited or no English skills and a lack of translators, women affected by FGM may have poor access to health care services.

There is clearly a need for more education to be provided to nurses and midwives, and indeed all healthcare professionals, about FGM, including the cultural aspects. This could occur through their initial educational qualification but also include continuing professional education through organisations and professional bodies. Included in this education would be how to support and care for women with FGM. In addition, there is a need to provide healthcare professionals with knowledge of culture sensitivity and role plays on how to ask difficult questions. ${ }^{[35]}$ There is also a need for more specific services in the Shepparton area to appropriately provide healthcare services to this group of women and their families.

\section{Conclusions}

Female genital mutilation is a significant global health concern and will become increasingly important in destination countries such as Australia. Specifically, for the Sudanese refugees who are being settled in the Shepperton Area of Victoria, Australia, there is a high incidence of FGM in the Sudanese population which provide unique healthcare challenges that need addressing. It could be argued that healthcare professional, especially nurses and midwives, are ill equipped to care for women who have undergone FGM. As such there is a need to increase the education available in undergraduate, postgraduate and continuing professional education programs on the care and supported needed for FGM women.

\section{Postscript}

On the 22nd April 2020, the Council of Ministers of Sudan's new government outlawed the practice of female genital mutilation. ${ }^{[36]}$ The new government was created following the ousting of former dictator Omar al-Bashir. Under an amendment to Sudan's criminal code, anyone who performs female genital mutilation faces a possible three-year prison term. ${ }^{[37,38]}$ Despite being good news, the law must still be ratified by a joint meeting of the Cabinet and the sovereign council. However, because FGM is deeply entrenched in Sudan's society, it is unclear whether the country's military leaders, who make up a majority of the sovereign council, will approve the law. There is concern that it could spark a backlash by powerful Islamist groups that backed al-Bashir. ${ }^{[36-38]}$

\section{CONFLiCTS OF INTEREST Disclosure}

The authors declare they have no conflicts of interest.

\section{REFERENCES}

[1] World Health Organisation. Sudan. 2016. Available from: https: //www.who.int/countries/sdn/en/

[2] World Health Organisation. 10 things to know about the health of refugees and migrants. 2019. Available from: https://www. wh o. int/news-room/feature-stories/detail/10-things- $t$ o-know-about-the-health-of-refugees-and-migrants

[3] United Nations Refugee Agency. South Sudan Refugee Crises Explained. 2019. Available from: https : //www. unref ugees.org/n ews/south-sudan-refugee-crisis-explained/

[4] Dawson AJ, Turkmani S, Varol N, et al. Midwives experiences of caring for women with female genital mutilation: insights and ways forward for practice in Australia. Women and Birth. 2015; 28(3): 207-214. PMid: 25686876. https ://doi.org/10.1016/j. womb i. 2015.01 .007

Published by Sciedu Press
[5] Thorogood C, Crowther S. Challenges to women's health. In: Pariman S, Pincombe J, Thorogood C, Tracy S. Midwifery. Preparation for Practice. 3rd ed. Churchill Livingston: Edinburgh; 2015.

[6] Ethnic Council of Shepparton and District Inc. Sudanese Community Profile. Available from: https://ethniccouncilsheppar ton.com.au

[7] Australian Bureau of Statistics. 2016 Census QuickStats. 2016. Available from: https://quickstats.censusdata.abs.gov. au/census_services/getproduct/census/2016/quicksta $t / 216$

[8] Moran A, Mallman M. Understanding Social Cohesion in Shepparton and Mildura. 2015. Melbourne: Victorian Multicultural Commission.

[9] Strong G. Shepparton shines as a haven with no room for racism. The Age. 7 July, 2010.

[10] Russell G, Harris M, Cheng IH, et al. Coordinated primary health care for refugees: a best practice framework for Australia. Report 
to the Australian Primary Health Care Research Institute. 2013. Available from: http://www.refugeehealthnetworkqld.org. $\mathrm{au} / \mathrm{wp}$-content/uploads/2019/07/Coordinated-PHC-for -Refugees_FULL-REPORT-1.pdf

[11] Goulburn Valley Health. About us. 2019. Available from: http: //www.gvhealth.org.au/

[12] American Psychological Association. Work, stress, and health and socioeconomic status. 2019. Available from: https://www . apa.or $\mathrm{g} / \mathrm{pi} / \mathrm{ses} / \mathrm{res}$ ources/publications/work-stress-health

[13] Australian Human Rights Commission. African Australians: human rights and social inclusion issues project. 2010. Available from: https ://www . humanrights.gov . au/our-work/race-discr imination/projects/african-australians-compendiu $m-2010$

[14] Singleton G, Williams J, Paxton G. Australian Refugee Health Practice Guide. Women's Health. 2019. Available from: http: //refugeehealthguide.org.au/womens-health/

[15] Zurynski Y, Phu A, Sureshkumar P, et al. Female genital mutilation in children presenting to Australian paediatricians. Archives of Disease in Childhood. 2017; 102(6): 509-515. PMid: 28082321. https://doi.org/10.1136/archdischild-2016-311540

[16] World Health Organisation. Female genital mutilation. 2018 [Assessed at October 10, 2019]. Available from: https://www. who.int/news-room/fact-sheets/deta il/female-genital-mutilation

[17] Raymond D, Khanlari S, Hansen S, et al. A qualitative study into the health and social care needs and barriers to service access for Sudanese women living in a socioeconomically disadvantaged area of Sydney, Australia. International Journal of Integrated Care. 2019; 19(4). https ://doi.org/10.5334/ijic.s3120

[18] Safari F. A qualitative study of women's lived experience after deinfibulation in the UK. Midwifery. 2013; 29: 154-158. PMid: 23084491. https://doi.org/10.1016/j.midw.2011.12.005

[19] Odemerho BI, Baier M. Female genital cutting and the need for culturally competent communication. The Journal for Nurse Practitioners. 2012; 8(6): 1-6. https ://doi.org/10.1016/j.nurpra .2011 .10 .003

[20] Pettersson KO. The Unbidden Pain: An African woman's Challenge of the Age-old Practice of Female Genital Mutilation. African Journal of Midwifery and Women's Health. MA Healthcare Ltd. 2014.

[21] Mulongo P, Martin CH, McAndrew S. The psychological impact of Female Genital Mutilation/Cutting (FGM/C) on girls/women's mental health: a narrative literature review. Journal of Reproductive and Infant Psychology. 2014; 32(5): 469-485. https : //doi.org/ 10.1080/02646838.2014.949641

[22] Von Rege I, Campion D. Female genital mutilation: implications for clinical practice. British Journal of Nursing. 2017; 26(18): 822-827. PMid: 29034707. https://doi.org/10.12968/bjon.2017.26. 18.S22

[23] Akinbiyi T, Langston E, Percec I. Female Genital Mutilation Reconstruction for Plastic Surgeons-A Call to Arms. Plastic and Reconstructive Surgery - Global Open. 2018; 6(11): e1945-e1945. PMid: 30881780. https://doi.org/10.1097/GOX.00000000000019 45

[24] Thakar R, Sultan AH, Raynor MD, et al. Care of the perineum, repair and female genital mutilation. In Marshall J \& Raynor M. Myles Textbook for Midwives. 16th ed. Churchill Livingstone: Edinburgh; 2014.

[25] Moxey JM, Jones LL. A qualitative study exploring how Somali women exposed to female genital mutilation experience and per- ceive antenatal and intrapartum care in England. BMJ Open. 2016; 6 : e009846. PMid: 26743705. https ://doi.org/10.1136/bmjope n-2015-009846

[26] Larsen U, Okonofua FE. Female circumcision and obstetric complications. International Journal of Gynecology \& Obstetrics. 2002; 77(3): 255-265. https://doi.org/10.1016/S0020-7292(02 ) 00028-0

[27] Chibber R, El-Saleh E, El Harmi J. Female circumcision: obstetrical and psychological sequelae continues unabated in the 21 st century. The Journal of Maternal-Fetal \& Neonatal Medicine. 2011; 24(6): 833-836. PMid: 21121711 https ://doi.org/10.3109/147670 58.2010 .531318

[28] Creighton S, Hodes D. Female genital mutilation: what every paediatrician should know. Archives of Disease in Childhood. 2016; 101(3): 267-71. PMid: 25791840. https://doi.org/10.1136/archdi schild-2014-307234

[29] Lundberg PC, Gerezgiher A. Experiences from pregnancy and childbirth related to female genital among Eritrean immigrant women in Sweden. Midwifery. 2006; 24: 214-225. PMid: 17316934. https://doi.org/10.1016/j.midw.2006.10.003

[30] Ahmed H, Shabu S, Shabila N. A qualitative assessment of women's perspectives and experience of female genital mutilation in Iraqi Kurdistan Region. BMC Women's Health. 2019; 19(1): 66. PMid: 31096978. https : //doi .org/10.1186/s12905-019-0765-7

[31] Jones L, Danks E, Clarke J, et al. Exploring the views of female genital mutilation survivors, their male partners and healthcare professionals on the timing of deinfibulation surgery and NHS FGM care provision (the FGM Sister Study): protocol for a qualitative study. BMJ Open. 2019; 9: e034140. PMid: 31628134. https ://doi.org/10.1136/bmjopen-2019-034140

[32] Kahn S. You see, one day they cut: The evolution, expression, and consequences of resistance for women who oppose female genital cutting. Journal of Human Behavior in the Social Environment. 2016; 26(7/8): 622-635. https : //doi .org/10.1080/10911359. 2016. 1238805

[33] Bryant RA, Edwards B, Creamer M, et al. The effect of post-traumatic stress disorder on refugees' parenting and their children's mental health: a cohort study. The Lancet Public Health. 2018; 3(5): e249e258. https://doi.org/10.1016/S2468-2667 (18)30051-3

[34] Vissandjée B, Denetto S, Migliardi P, et al. Female Genital Cutting (FGC) and the ethics of care: community engagement and cultural sensitivity at the interface of migration experiences. BMC International Health and Human Rights. 2014; 14(1): 13. PMid: 24758156. https : //doi .org/10.1186/1472-698X-14-13

[35] Fenton C, Jones LK. Towards achieving cultural sensitivity in Aboriginal maternity care. International Journal of Health Sciences. 2015; 3(1): 23-38. https://doi .org/10.15640/ijhs.v3n1a2

[36] Australian Broadcasting Commission. Sudan moves to ban female genital mutilation with landmark law. May 3, 2020 [Assessed at June 6, 2020]. Available from: https://www.abc.net.au/news/20 20-05-03/sudan-moves-to-ban-female-genital-mutilat ion-with-landmark-law/12209374

[37] Walsh D. In a Victory for women in Sudan, female genital mutilation is outlawed. New York Times. April 30, 2020 [Assessed at June 6, 2020]. Available from: https : //www.nytimes.com/2020/04/30/world/afric a/sudan-outlaws-female-genital-mutilation-.html

[38] Salih MZ. Sudan to outlaw female genital mutilation. The Guardian. May 2, 2020 [Assessed at June 6, 2020]. Available from: https://www. theguardian.com/society/2020/may/0 $1 /$ sudan-to-outlaw-female-genital-mutilation-fgm 